\title{
Um Estudo de Revisão do Inventário de Ciúme Romântico (ICR)
}

\author{
A Review of the Romantic Jealousy Inventory (RJI)
}

\author{
José Maurício Haas Bueno*, ${ }^{*}$ \& Lucas de Francisco Carvalho ${ }^{b}$ \\ ${ }^{a}$ Universidade Federal de Pernambuco, Sergipe, Brasil \& ${ }^{b}$ Universidade São Francisco, Itatiba, Brasil
}

\begin{abstract}
Resumo
O objetivo deste estudo foi revisar o Inventário de Ciúme Romântico, na tentativa de obter um instrumento com melhores propriedades psicométricas. O instrumento revisado foi aplicado a 201 universitários de ambos os sexos. Uma análise fatorial exploratória revelou uma estrutura primária com seis fatores: Não Contato com o Parceiro, Contato Parceiro-Rival, Agressão ao Parceiro, Agressão ao Rival, Autoestima e Investigação. Uma análise fatorial de segunda ordem indicou a unidimensionalidade dos seis fatores primários. A fidedignidade $(\alpha)$ variou de 0,55 (Investigação) a 0,91 (Fator Geral). Portanto, a escala apresenta validade baseada na estrutura interna, mas a fidedignidade sofreu influência do baixo número de itens em alguns fatores. Entretanto, a escala pode ser recomendada para utilização em pesquisas, especialmente para avaliação global do ciúme romântico.

Palavras-chave: Avaliação psicológica, psicometria, ciúme.
\end{abstract}

\begin{abstract}
The aim of this study was to review the Romantic Jealousy Inventory in an attempt to obtain an instrument with better psychometric properties. The reviewed instrument was administered to 201 undergraduate students of both sexes. An exploratory factor analysis revealed a primary structure with six factors: NonContact with Partner, Partner-Rival Contact, Partner Assault, Rival Assault, Self-Esteem and Investigation. A second-order factor analysis indicated the unidimensionality of the six primary factors. Reliability $(\alpha)$ ranged from .55 (Investigation) to .91 (General Factor). Therefore, the scale presents validity based on internal structure, but reliability was influenced by the low number of items in some factors. However, the scale may be recommended to be used in research, especially for an overall assessment of romantic jealousy.

Keywords: Psychological assessment, psychometrics, jealousy.
\end{abstract}

A manifestação do ciúme vem sendo retratada em importantes obras literárias ao longo da história. Por exemplo, o assassinato de Abel por seu irmão, Caim, é retratado na Bíblia como motivado pelo ciúme, assim como o assassinato de Desdêmona, por seu marido, retratado por Shakespeare em Otelo, o Mouro de Veneza. Ainda hoje, o potencial atrativo do ciúme continua a arrebanhar milhões de espectadores por meio de filmes, seriados e novelas, além das manchetes de jornal, que frequentemente noticiam crimes motivados pelo ciúme.

No contexto psicológico, o ciúme é frequente em diversas situações. Na clínica, aparece como o tema central de dificuldades no relacionamento amoroso e sexual (Marks \& de Silva, 1991; White \& Mullen, 1989), como principal sintoma do Transtorno delirante - Tipo ciumento (American Psychiatric Association [APA], 2003), asso-

\footnotetext{
*Endereço para correspondência: Centro de Filosofia e Ciências Humanas, Departamento de Psicologia, Universidade Federal de Pernambuco, Av. Arquitetura, s/ n, $8^{\circ}$ Andar, Cidade Universitária, Recife, PE, Brasil 50740-550. E-mail: mauricio.bueno@ufpe.br e talktomau@gmail.com
}

ciado a outros transtornos, como o Obsessivo-Compulsivo (Torres, Ramos-Cerqueira, \& Dias, 1999) e o Borderline (Dutton, van Ginkel, \& Landolt, 1996) ou a traços psicológicos, como o neuroticismo (Carvalho, Bueno, \& Kebleris, 2008) e a baixa autoestima (DeSteno, Valdesolo, \& Bartlett, 2006). Pesquisas mostram, ainda, sua estreita relação com comportamentos violentos, especialmente contra a mulher (Holtzworth-Munroe, Stuart, \& Hutchinson, 1997; Mullen, 1995), e com estresse no trabalho (Vecchio, 2000), tornando-o também um tema de interesse para as áreas de psicologia social, criminal e do trabalho, entre outras.

De fato, o ciúme é uma reação emocional extremamente usual, manifestada em diversos tipos de relacionamentos interpessoais, como entre parceiros amorosos (por exemplo, De Silva, 1997), pais e filhos (por exemplo, Masciuch \& Kienapple, 1993) ou amigos (por exemplo, Parker, Low, Walker, \& Gamm, 2005). Entretanto, este trabalho enfoca apenas a ocorrência desse fenômeno em relacionamentos amorosos, quando recebe a denominação de ciúme romântico (por exemplo, White, 1981). Por isso, doravante, sempre que o termo ciúme for utilizado, os autores estarão se referindo ao ciúme romântico. 
Mais especificamente, preocupamo-nos com a mensuração do ciúme, incluindo sua manifestação patológica, uma vez que os instrumentos encontrados para sua avaliação são, em sua maioria, antigos e desenvolvidos em outros idiomas e culturas. Apenas dois instrumentos para população brasileira foram encontrados (Carvalho et al., 2008; Ramos, Yazawa, \& Salazar, 1994), e ambos apresentam limitações que justificam o investimento em um terceiro instrumento. Assim, uma breve revisão dos conceitos empregados para a construção de um novo instrumento para avaliação do ciúme romântico é apresentada a seguir.

\section{Ciúme: Definição, Manifestação e Medida}

É possível encontrar várias definições de ciúme na literatura científica, sendo que cada autor destaca e/ou acrescenta um aspecto relacionado a esse construto. White (1981), por exemplo, considera o ciúme como um complexo de emoções, cognições e comportamentos destinados a proteger o relacionamento e/ou a autoestima, diante da presença de um rival, real ou imaginário, a um relacionamento amoroso. Buunk e Bringle (1987) ressaltam a qualidade desagradável dessa experiência e acrescentam que o ciúme pode ser sentido em relação a um parceiro amoroso atual ou a um ex-parceiro e uma terceira pessoa. De Silva (1997), por sua vez, acrescenta que o ciúme também pode ser sentido em decorrência de um relacionamento que o atual parceiro amoroso teve no passado. Essas e outras definições citadas na literatura (por exemplo, DeSteno \& Salovey, 1996; Pines, 1998), frequentemente se referem a três pontos: (a) o ciúme é uma reação emocional complexa e desagradável, que envolve sentimentos (especialmente os de raiva, ansiedade e tristeza), cognições e tendências comportamentais; (b) a reação ocorre devido à percepção de ameaça a um relacionamento considerado importante; e, (c) a ameaça é representada por um rival, que pode ser real ou imaginário.

Apesar de essas reações serem geralmente associadas a tragédias, o ciúme é antes um fenômeno normal, decorrente da evolução humana em sociedade (Buss, Larsen, Western, \& Semmelroth, 1992). Ao adotar a convivência em grupo como estratégia de sobrevivência e preservação da espécie, o homem tornou-se um ser social. Em consequência disso, os relacionamentos de todos os tipos foram valorizados, tornando-se alvo de competição, inclusive os amorosos. Do ponto de vista evolutivo, o ciúme surge, e evolui ao longo do tempo, como um dispositivo emocional destinado a proteger a estabilidade de relacionamentos amorosos considerados importantes (DeSteno et al., 2006).

Entretanto, o ciúme pode se manifestar de forma saudável ou patológica. Segundo Pfeiffer e Wong (1989), o ciúme saudável é o que se segue à percepção de ameaça real, provocando algum sofrimento (reação emocional) e desencadeando ações (reação comportamental) de proteção ao relacionamento. Por sua vez, a reação patológica pode envolver ameaça imaginada ao relacionamento (de- lírios de infidelidade), suspeita paranoide de estar sendo traído, sofrimento mais intenso do que na reação normal de ciúme e comportamentos de investigação.

A manifestação do ciúme saudável muitas vezes é percebida como um sinal de afeição e amor, ou seja, de que uma pessoa se preocupa, se importa com a outra, e não a quer perder (De Silva, 1997). Contudo, a manifestação patológica do ciúme faz com que uma pessoa se comporte de forma ambivalente em relação ao parceiro, ora amando, ora desconfiando. Essa labilidade afetiva é que costuma deteriorar o relacionamento, em razão das frequentes acusações de traição, suspeitas, tentativas de controle do parceiro e comportamentos agressivos, que mais afastam o parceiro do que o atraem (Almeida, Rodrigues, \& Silva, 2008).

Subjacente à ideia de que o ciúme pode se manifestar de forma saudável e patológica está a noção de que há diferenças individuais na manifestação do ciúme. A teoria da exclusividade (Soble, 1990), pode facilitar o entendimento da origem dessas diferenças no contexto dos relacionamentos amorosos. Segundo esse autor, em qualquer relacionamento algumas regras são assumidas, na maioria das vezes implicitamente, quanto à exclusividade mútua que os parceiros se reservarão na execução de certas atividades. No caso de relacionamentos amorosos, a exclusividade sexual opera muito fortemente em várias e diferentes culturas. A violação da exclusividade sexual, geralmente, constitui-se em motivo suficiente para o rompimento do relacionamento. Entretanto, há outros domínios em que a exclusividade é discutível, como conversar, dançar, abraçar ou telefonar para outra pessoa, que não o parceiro ou parceira de um relacionamento amoroso. Enquanto no primeiro caso a influência cultural é bastante grande, no segundo, a influência é mais disposicional (De Silva, 1997), isto é, depende em grande parte das crenças e predisposições emocionais desenvolvidas ao longo da história pessoal de cada um.

Assim, podemos inferir que as diferenças individuais na manifestação do ciúme vêm em parte da cultura e em parte das predisposições psicológicas (incluindo as temperamentais), que, por sua vez, operam sobre a extensão com que a exclusividade mútua será entendida entre parceiros amorosos. Essas predisposições influenciam não somente o aparecimento da reação de ciúme como também o curso que ela irá tomar. A baixa autoestima é um desses fatores disposicionais que têm sido freqüentemente associados ao ciúme (Demirtas, \& Dönmez, 2006; Mathes, Adams, \& Davies, 1985; Nadler \& Dotan, 1992). Em um estudo experimental sobre o tema, DeSteno et al. (2006) mostraram que a autoestima medeia a percepção da interação parceiro-rival e a intensidade com que o ciúme será sentido. Ou seja, diante da percepção da interação do parceiro com um rival, o que se sucede é uma avaliação implícita do grau com que essa interação irá afetar a autoestima do parceiro rejeitado. Quanto maior for a afetação da autoestima, maior será a intensidade do ciúme sentido pelo parceiro rejeitado. E quanto maior a intensi- 
dade do ciúme, maior a probabilidade de que a reação seja agressiva.

Resultados semelhantes foram encontrados em outro estudo, que verificou que a infidelidade feminina provoca danos à reputação masculina (autoestima), particularmente em culturas em que a honra masculina é valorizada (uma amostra brasileira foi empregada como representante desse tipo de cultura). Nesse tipo de cultura, os autores verificaram ser mais comum o emprego da violência como forma de restaurar os danos causados à reputação masculina (Vandello \& Cohen, 2003).

Como se pode notar, a autoestima ferida parece estar em estreita relação com o aparecimento da agressividade, uma reação muito característica da pessoa que apresenta o ciúme. Há muitos motivos que podem precipitar uma reação agressiva, entre os mais comuns estão a percepção da ocorrência de uma infidelidade (sexual), a perda de poder e do controle sobre o parceiro, a perda do parceiro para uma terceira pessoa (envolvimento afetivo), a perda dos sonhos e planos para o futuro. Independentemente de essas percepções serem reais ou imaginárias, elas conduzem a sentimentos de raiva, ressentimento, desespero, dor, que, por sua vez, aumentam as chances de que um comportamento violento apareça (Mullen, 1995).

Mullen e Martin (1994) afirmam que não há diferença no número de vezes em que homens e mulheres se dizem ameaçados ou atacados pelos respectivos parceiros. Entretanto, a superioridade física dos homens faz com que os danos causados às mulheres sejam infinitamente superiores e mais graves do que os causados por elas à eles. Mullen (1995) afirma ainda que o risco de violência é maior quando: o ciúme é patológico, há histórico anterior de violência motivada pelo ciúme, a pessoa ciumenta também é agressiva em outras circunstâncias, há abuso de álcool e drogas, os conflitos do casal incluem ameaças e vêm numa escalada contínua, a pessoa ciumenta é depressiva com predisposição evidente ao suicídio e quando o ambiente cultural de que o ciumento é proveniente é complacente com o uso da violência em casos de infidelidade.

Apesar da frequência com que se manifesta e da gravidade das consequências observadas por sua manifestação, o ciúme tem sido pouco estudado, especialmente quanto à sua avaliação. A maioria dos instrumentos de medida frequentemente referida na literatura, data dos anos 70 e 80 e é de difícil recuperação, já que se trata de comunicações em congressos (Benedictson, 1977; Bryson, 1976, 1977; Hupka \& Bachelor, 1979; Rosmarin, Chambless, \& LaPointe, 1979; Rusch \& Hupka, 1977; White, 1980 ). Por isso, informações sobre instrumentos estrangeiros só são encontradas nas descrições dos métodos de estudos que envolveram tal mensuração, muitas vezes citadas por outros autores. Por exemplo, Nadler e Dotan (1992) descrevem a Dispositional Jealousy Scale, composta por 14 itens para mensuração unidimensional e fidedigna do ciúme $(\alpha=0,85)$. Outra escala unidimensional usualmente referida é a Interpessoal Jealousy Scale
(Mathes, Phillips, Skowran, \& Dick, 1982, citados por De Silva, 1997), que é composta por 27 itens, para serem avaliados por meio de uma escala de nove pontos, de -4 , absolutamente falso, a 4, absolutamente verdadeiro. Embora o coeficiente de fidedignidade não seja informado, a autora sugere que a escala seja consistente.

Em outra linha, mais em conformidade com a proposição do ciúme como um fenômeno psicológico complexo, muitos autores sugerem que sua avaliação deve ser multifatorial (Mathes, 1992; Pfeiffer \& Wong, 1989; Pines, 1992). Um exemplo de escala multifatorial é o Romantic Jealousy Questionnaire ([RJQ], Pines \& Aronson, 1983, citados por Demirtas \& Dönmez, 2006). Este questionário é respondido por meio de uma escala de sete pontos, em que 1 significa "nunca verdadeiro para mim" e 7 "sempre verdadeiro para mim". São obtidas pontuações em cinco domínios: intensidade do ciúme, reações de ciúme (física, emocional, cognitivo), formas de enfrentamento do ciúme e causas e efeitos do ciúme. O número de itens e os coeficientes de fidedignidade de cada escala não foram informados.

Outra importante escala para avaliação multifatorial do ciúme é a Multidimensional Jealousy Scale (MJS). Este instrumento foi concebido para a avaliação dos aspectos cognitivos, emocionais e comportamentais do ciúme romântico. Três estudos atestaram a estabilidade da estrutura fatorial dessa escala, cuja porcentagem de variância explicada pelos três fatores foi sempre superior a 50\%, e os bons índices de consistência interna, que foram sempre superiores a 0,80 (Pfeiffer \& Wong, 1989).

Todos esses instrumentos foram desenvolvidos em outros contextos culturais, são de difícil recuperação e são antigos, especialmente se considerarmos que a manifestação do ciúme pode ter sido profundamente afetada pela evolução dos valores sexuais ocorrida ao longo dos anos 80,90 e 2000 e pelo desenvolvimento tecnológico, que proporcionou novas formas de comunicação, como o telefone celular e a internet. Instrumentos mais recentes para avaliação do ciúme e com informações mais completas foram encontradas na literatura científica brasileira (Carvalho et al., 2008; Ramos et al., 1994). No instrumento desenvolvido por Ramos et al. (1994), os 58 itens foram agrupados em três fatores, com bons índices de consitência interna. O primeiro fator, não ameaça $(\alpha=0,87)$, se refere a não perturbalidade da relação pela interferência de uma terceira pessoa. O segundo fator, exclusão $(\alpha=0,85)$, é composto por itens que descrevem o enfraquecimento da relação do casal pela interferência de um rival. E o terceiro fator, interferência $(\alpha=0,77)$, é composto por itens relacionados a reações agressivas provocadas pela interferência de um rival. Embora tenha apresentado boas propriedades psicométricas, esse instrumento foi construído a partir de descrições dos participantes de situações provocadoras de ciúme, carecendo de uma fundamentação teórica psicológica. Talvez por isso mesmo, não contempla a avaliação de certos aspectos frequentemente 
associados ao ciúme, especialmente em sua manifestação patológica, como os comportamentos de investigação, agressividade e baixa autoestima.

Um novo instrumento, mais apoiado em teorias psicológicas, foi construído pelo autor (Ramos, 1998), que encontrou novamente três fatores com eigenvalues superiores a 1,5 e bons índices de fidedignidade. Os fatores encontrados foram aceitação, dor e raiva. Os itens de aceitação descrevem situações ambíguas (como o parceiro ou parceira ir a uma festa sozinha) e de interação entre o parceiro ou parceira com uma terceira pessoa (por exemplo, ser paquerada por um amigo seu), que são consideradas normais pelo parceiro supostamente excluído. A escala de dor é composta por itens que descrevem situações de desconforto emocional (por exemplo, incômodo, irritação, indignação) em situações em que há interação entre o parceiro ou parceira e um suposto rival, ou que sugerem que tal interação é possível. A escala de raiva descreve situações de indignação, raiva, fúria, mas também de indecência, vergonha em situações que descrevem ou sugerem uma interação com um rival. Este novo instrumento apresenta avanços em relação ao anterior quanto ao embasamento teórico, mas continua apresentando uma escala relacionada com a não ocorrência de ciúme e duas outras cuja interpretação não é limpa. Por exemplo, a escala de raiva, também apresenta itens relacionados com vergonha e indecência; a escala de dor também apresenta itens que descrevem reações de raiva, indignação e irritação e, por fim, três itens apresentam cargas fatoriais em ambas as escalas.

Outro instrumento brasileiro (Carvalho et al., 2008) é composto por 28 itens distribuídos em uma estrutura de seis fatores. O primeiro fator, ciúme romântico, descreve a ocorrência de reações negativas frente ao contato do parceiro ou parceira com possíveis rivais ou a impossibilidade de manter algum tipo de contato ou comunicação com o parceiro ou parceira. O segundo fator, não ciúme, descreve situações em que a presença de um suposto rival não é considerada perigosa ao relacionamento, assim como o Fator 3, não agressão, que descreve a manifestação de comportamentos não agressivos. O quarto fator, desconfiança, se refere ao sentimento de desconfiança quando é impossível se comunicar ou obter informações a respeito do parceiro. O quinto fator, investigação, diz respeito à procura de sinais de infidelidade do parceiro. $\mathrm{O}$ sexto e último fator, insegurança, se refere à insegurança quanto ao compromisso do parceiro com o relacionamento. Esses seis fatores primários se reagruparam em apenas dois fatores de segunda ordem, relacionados à ocorrência (FSO1 - ciúme) e a não ocorrência (FSO2 não ciúme) de reações de ciúme romântico, respectivamente. A fidedignidade ficou sempre acima de 0,70, com exceção do quinto fator, que apresentou alfa igual a 0,62. Em ambos os fatores de segunda ordem a fidedignidade foi de 0,89 . Ao lado disso, observou-se que todos os fatores relacionados a alguma forma de manifestação do ciúme romântico (Fatores 1, 4, 5 e 6) correlacionaram-se positiva e significativamente com o traço de neuroticismo, constituindo-se em evidências de validade por meio da correlação com critérios externos, para interpretações realizadas utilizando o instrumento. Os autores consideraram esses resultados como encorajadores, mas sugeriram uma revisão da escala com vistas à melhoria da representação comportamental de fatores que ficaram com um baixo número de itens e a eliminação dos fatores não relacionados à ocorrência de ciúme romântico.

Considerando a frequência e as graves consequências físicas e psicológicas da manifestação do ciúme, e a necessidade de um instrumento atualizado e teoricamente fundamentado para avaliação desse construto, que pode representar uma grande contribuição aos profissionais na área clínica, na observação de condições psicopatológicas relacionadas ao ciúme romântico, é que os autores propõem a revisão do Inventário de Ciúme Romântico (Carvalho et al., 2008), com vistas à obtenção de um instrumento com melhores propriedades psicométricas. Especificamente, procedeu-se a uma revisão dos itens do instrumento, fundamentando-os teoricamente, na tentativa de obtenção apenas de fatores relacionados com a ocorrência (e não com a ausência) de ciúme, especialmente em sua manifestação patológica, com validade fatorial e consistência interna superior a 0,7 .

\section{Lógica da Revisão do Instrumento}

Parte das frases que constituem o instrumento foi elaborada com base na ideia central de o ciúme ser despertado pela percepção de envolvimento do parceiro amoroso com um rival (Buunk \& Bringle, 1987; De Silva, 1997; DeSteno \& Salovey, 1996; Pines, 1998; White, 1981). Além disso, foram utilizados os 27 itens da versão original do instrumento ([ICR], Carvalho et al., 2008), ainda que tenham sido modificados em alguns casos. Assim, a estrutura dessas frases contempla a descrição de uma interação parceiro-rival, seguida por algum tipo de reação. A interação parceiro-rival descreve situações que podem ser interpretadas como uma violação da exclusividade entre os parceiros (Soble, 1990; por exemplo, "Quando meu parceiro abraça outra mulher. . .") e as reações a essas situações podem ser cognitivas (por exemplo, “... penso que pode haver alguma coisa entre eles"), emocionais (por exemplo, ". . fico com raiva”) ou comportamentais (por exemplo, “... tomo o telefone da mão dele e desligo" ${ }^{1}$. Essas frases podem ser consideradas como representantes do ciúme saudável (Pfeiffer \& Wong, 1989), já que descrevem a interação parceiro-rival e, por isso, algum tipo de reação de ciúme é esperada.

Dada as associações da baixa autoestima (Demirtas \& Dönmez, 2006; DeSteno et al., 2006; Mathes et al., 1985; 
Nadler \& Dotan, 1992) e da agressividade (Mullen, 1995; Mullen \& Martin, 1994; Vandello \& Cohen, 2003) com reações mais patológicas do ciúme, algumas frases descrevem esses tipos de reações, diante de um cenário de possível envolvimento do parceiro com um rival. A baixa autoestima é representada especialmente por crenças (reações cognitivas) quanto a ser inferior ao parceiro no relacionamento, como o principal motivo pelo interesse do parceiro por um rival. A agressividade é representada por reações comportamentais, como quebrar pertences do parceiro, "perder as estribeiras", gritar, entre outras.

Ao lado disso, os aspectos mais delirantes do ciúme patológico (Pfeiffer \& Wong, 1989) são difíceis de contemplar num instrumento de autorrelato, uma vez que a principal diferença entre delirante e não delirante é a fundamentação na realidade. Entretanto, na tentativa de representar esse tipo de reação própria do ciúme, foram elaboradas frases em que um desejado contato com o parceiro não é conseguido (por exemplo, o parceiro deixa o celular desligado, não telefona ou não é encontrado onde disse que estaria) e, em razão disso, surgem reações de ciúme por uma suposta infidelidade do parceiro com um também suposto rival.

Finalmente, outro tipo de reação frequentemente relacionado com o ciúme patológico são os comportamentos de investigação e procura de pistas de infidelidade (Pfeiffer \& Wong, 1989). Exemplos de comportamentos desse tipo contemplados no instrumento são a contratação de um detetive particular para seguir o parceiro, tentar descobrir a senha do email do parceiro, entre outros.

Dadas as características dos itens elaborados, era esperada a formação de três fatores compatíveis com as reações emocionais, cognitivas e comportamentais relativas ao ciúme, tal como obtido por Pfeiffer e Wong (1989). Adicionalmente, os resultados obtidos por Carvalho et al. (2008), do qual a presente escala é derivada, também sugerem a possibilidade de obtenção de mais três fatores relacionados com reações agressivas, de baixa autoestima e a comportamentos de investigação, independentemente das reações serem de natureza emocional, cognitiva ou comportamental.

\section{Método}

\section{Participantes}

Os dados foram obtidos com uma amostra de conveniência, composta por 201 estudantes universitários de uma instituição de ensino superior particular da cidade de São Paulo. A amostra foi predominantemente feminina (61\%), com idades entre 18 e 53 anos, com média de idade igual a 22,4 e desvio padrão igual a 5,7.

\section{Instrumento}

O Inventário de Ciúme Romântico - Revisado (ICRR) ficou inicialmente composto por 37 itens que descreviam a ocorrência de reações de ciúme romântico conforme descrito anteriormente (outros quatro itens que descreviam reações de ausência de ciúme não entraram na análise). Os sujeitos foram instruídos a ler as afirmações e atribuir suas respostas por meio de uma escala de cinco pontos, na qual "1" correspondia a uma afirmação "nada característica" e " 5 " a uma afirmação "totalmente característica" do comportamento normalmente apresentado pelo respondente. Além disso, conforme procedimento adotado por Buss et al. (1992), os participantes foram instruídos a basearem suas respostas em um relacionamento amoroso que tiveram, que tinham naquele período ou que gostariam de ter.

\section{Procedimento e Análise dos Dados}

O instrumento foi aplicado em universitários, coletivamente, em situação de sala de aula, após a obtenção de seu consentimento livre e esclarecido. As respostas dos sujeitos foram digitadas em planilha eletrônica e submetidas a análises estatísticas. Análises fatoriais exploratórias, de primeira e de segunda ordem, foram empregadas para verificação de evidências de validade baseadas na estrutura interna (American Educational Research Association [AERA], American Psychological Asso-ciation, \& National Council on Measurement in Education [NCME], 1999), e o Coeficiente Alfa de Cronbach foi empregado como indicador da consistência interna do instrumento. Os resultados são apresentados a seguir.

\section{Resultados}

Para verificação da adequação da amostra à análise fatorial foi empregada a medida de adequação da amostra de Kaiser-Meyer-Olkin (KMO) e o teste de esfericidade de Bartllet. O KMO foi de 0,86, indicando uma boa adequação dos dados à análise fatorial, e o teste de esfericidade de Bartlett foi significativo ao nível de 0,001 $\left(\chi^{2}=3234 ; g l=666\right)$, mostrando que a matriz de correlações diferiu significativamente de uma matriz de identidade, podendo ser submetida à análise fatorial.

Assim, foi realizada uma análise fatorial exploratória, com extração dos fatores por análise dos componentes principais. Como uma análise da magnitude das correlações entre os componentes revelou valores baixos e próximos de zero, optou-se pela rotação varimax. Essa análise resultou na obtenção de nove fatores com eigenvalues acima de 1, responsáveis pela explicação de $64,2 \%$ da variância total. Entretanto, sete itens foram eliminados por apresentarem cargas superiores a $0,4 \mathrm{em}$ mais de um fator, por formarem um fator sozinho ou acompanhado de itens com cargas em outros fatores, e pela não interpretabilidade dos fatores. Assim, uma nova análise foi efetuada com os trinta itens restantes, impondo-se, com base no scree plot, a extração de seis fatores compostos apenas por itens com cargas superiores a $0,4 \mathrm{em}$ apenas um fator. As cargas fatoriais, os eigenvalues e os coeficientes alfa de Cronbach obtidos a partir dessa última análise são mostrados na Tabela 1. 
Tabela 1

Cargas Fatoriais, Eigenvalues, \% de Variância Explicada e Coeficientes Alfa de Cronbach

\begin{tabular}{|c|c|c|c|c|c|c|}
\hline Itens & 1 & 2 & 3 & 4 & 5 & 6 \\
\hline 10 & 0,776 & & & & & \\
\hline 21 & 0,766 & & & & & \\
\hline 13 & 0,761 & & & & & \\
\hline 27 & 0,734 & & & & & \\
\hline 2 & 0,719 & & & & & \\
\hline 17 & 0,711 & & & & & \\
\hline 23 & 0,673 & & & & & \\
\hline 20 & & 0,760 & & & & \\
\hline 15 & & 0,725 & & & & \\
\hline 7 & & 0,717 & & & & \\
\hline 26 & & 0,704 & & & & \\
\hline 12 & & 0,680 & & & & \\
\hline 4 & & 0,640 & & & & \\
\hline 29 & & & 0,671 & & & \\
\hline 6 & & & 0,659 & & & \\
\hline 28 & & & 0,637 & & & \\
\hline 8 & & & 0,625 & & & \\
\hline 5 & & & 0,583 & & & \\
\hline 9 & & & 0,501 & & & \\
\hline 18 & & & & 0,686 & & \\
\hline 16 & & & & 0,676 & & \\
\hline 14 & & & & 0,551 & & \\
\hline 22 & & & & 0,551 & & \\
\hline 19 & & & & & 0,797 & \\
\hline 11 & & & & & 0,766 & \\
\hline 24 & & & & & 0,625 & \\
\hline 30 & & & & & 0,588 & \\
\hline 25 & & & & & & 0,686 \\
\hline 3 & & & & & & 0,563 \\
\hline 1 & & & & & & 0,475 \\
\hline Eigenvalue & 4,8 & 3,7 & 2,9 & 2,4 & 2,1 & 1,9 \\
\hline \% Var. Expl. & 16,2 & 12,5 & 9,8 & 7,8 & 7,1 & 6,5 \\
\hline Álfa de Cronbach & 0,90 & 0,83 & 0,81 & 0,66 & 0,67 & 0,55 \\
\hline
\end{tabular}

Observa-se que os eigenvalues variaram de 1,9 a 4,8 , explicando unitariamente de 6,5 a $16,2 \%$ da variância total e, em conjunto, $59,9 \%$ da variância total. Os coeficientes alfa de Cronbach variaram de 0,55 a 0,90 , sendo superiores a 0,7 nos três primeiros fatores, próximos a esse valor nos fatores 4 e 5 e pouco abaixo no último fator.

O primeiro fator (F1 - Não Contato com o Parceiro) englobou itens que descrevem crenças ou pensamentos de infidelidade quando um contato com o parceiro não é conseguido, ou ante a perda de controle sobre a localização do parceiro. O segundo fator (F2 - Contato ParceiroRival) reuniu itens relacionados a reações emocionais típicas de ciúme frente à percepção do parceiro estabelecendo um relacionamento com um possível rival. Itens sobre reações agressivas voltadas para o parceiro foram reunidos no terceiro fator (F3 - Agressão ao Parceiro) e, de modo similar, o quarto fator (F4 - Agressão ao Rival) reuniu itens que descrevem reações agressivas voltadas para possíveis rivais ou reações impulsivas/histéricas quando o parceiro dá mais atenção a uma terceira pessoa. Os itens do quinto fator (F5 - Autoestima) se referem a reações nas quais o indivíduo atribui a si a culpa pela possibilidade de infidelidade do parceiro. Finalmente, o último fator (F6 - Investigação) reuniu itens que se referem a comportamentos de investigação relacionados à fidelidade do parceiro.

Para verificação da possibilidade de reagrupamento dos seis fatores primários em possíveis fatores de segunda ordem, procedeu-se a uma análise fatorial de segunda ordem. Como resultado, foi obtido um único fator, capaz 
Bueno, J. M. H. \& Carvalho, L. F. (2012). Um Estudo de Revisão do Inventário de Ciúme Romântico (ICR).

de explicar $49,4 \%$ da variância total. Entretanto, a autoestima apresentou carga fatorial definidamente inferior $(0,32)$ aos demais (todos superiores a 0,6$)$ nesse fa- tor de segunda ordem. A consistência interna desse fator geral foi de 0,91. A Tabela 2 apresenta as estatísticas descritivas dos seis fatores primários obtidos, bem como do fator obtido na matriz rotada de segunda ordem.

Tabela 2

Estatísticas Descritivas dos Seis Fatores

\begin{tabular}{lccccc}
\hline & $N$ & Min & Max & $M$ & $D P$ \\
\hline F1 - Não Contato & 199 & 1,00 & 5,00 & 1,7538 & 0,82415 \\
F2 - Contato Parceiro-Rival & 201 & 1,00 & 5,00 & 2,9577 & 0,93453 \\
F3 - Agressão ao Parceiro & 198 & 1,00 & 4,50 & 1,6322 & 0,72078 \\
F4 - Agressão ao Rival & 199 & 1,00 & 3,75 & 1,4008 & 0,54635 \\
F5 - Autoestima & 200 & 1,00 & 4,50 & 1,6487 & 0,70359 \\
F6 - Investigação & 201 & 1,00 & 4,67 & 1,5257 & 0,70909 \\
FSO - Total & 201 & 1,00 & 3,50 & 1,8896 & 0,53918 \\
\end{tabular}

As pontuações nos fatores foram calculadas pela média de pontos atribuídos aos itens que compõem cada fator. Portanto, em todas as escalas as pontuações podiam variar de 1 a 5 . A observação das médias mostra que houve tendência de base em todas as escalas, exceto no fator 2 (contato parceiro-rival), em que a média coincidiu com o centro da amplitude. Os desvios padrões mostram que também não houve muita variabilidade, especialmente nos fatores $4 \mathrm{e}$ Total, o que significa que os participantes tenderam a escolher apenas dois ou três pontos da escala de cinco, na atribuição das respostas.

\section{Discussão}

Neste trabalho, os autores procederam a uma revisão de uma escala anterior (Carvalho et al., 2008) para mensuração do ciúme romântico, visando a fundamentação teórica da escala, a obtenção apenas de fatores relacionados à ocorrência de ciúme romântico (e não com a sua ausência) e com boas propriedades psicométricas. Era esperada a obtenção de seis fatores, sendo três relacionados com as reações emocionais, cognitivas e comportamentais frente à percepção de uma (possível) interação parceiro-rival (Pfeiffer \& Wong, 1989), e outros três relacionados com reações agressivas, de baixa autoestima e de investigação, independentemente de serem emocionais, cognitivas ou comportamentais (Carvalho et al., 2008). Os resultados obtidos se assemelham às expectativas, mas algumas diferenças foram notadas e são discutidas a seguir.

Tal como esperado, foram encontrados fatores em que o tipo de reação (emocional, cognitiva ou comportamental) parece desempenhar algum papel. Entretanto, notase que a intensidade da reação também está presente na diferenciação dos fatores. Nesse sentido, o F2, contato parceiro-rival, ficou composto apenas por reações emocionais de baixa intensidade, como "me incomoda", "me sinto mal”, "é desagradável”, “é desconfortável”. Ao lado disso, essas reações surgem em decorrência de uma interação parceiro-rival presumivelmente real, porque é descrita na frase (por exemplo, "notar que o parceiro ou parceira olha, conversa, abraça outra pessoa, sexualmente atrativa). Essas características de uma reação de intensidade moderada a uma ameaça real a um relacionamento, foram descritas por Pfeiffer e Wong (1989) como características da manifestação saudável do ciúme romântico. Provavelmente, esse é o tipo de ciúme que, em consonância com padrões culturais, funciona como um sinal de alerta de que algo daquilo que deveria ser exclusivo entre os parceiros (Soble, 1990) está sob a ameaça de ser oferecido a uma terceira pessoa.

Assim o F2 da escala atual parece compatível com o F1 da escala original (Carvalho et al., 2008). No entanto, o grupo de itens da escala atual ficou mais homogêneo quanto ao conteúdo dos itens, já que seu correlato na escala original apresentava reações mais intensas e variadas (sentimentos de raiva e insegurança) e até um item relacionado com comportamento de investigação [ver as ligações e/ou mensagens no celular do (a) parceiro (a)]. Portanto, a revisão da escala proporcionou a confirmação de um fator com esse significado e tornou-o mais homogêneo em termos interpretativos.

As estatísticas descritivas apoiam a interpretação do F2 como associado a reações saudáveis do ciúme romântico, uma vez que é o único fator que apresenta média igual ao ponto central das opções de resposta $(M=3)$. Isto indica que as reações descritas nos itens deste fator são identificadas pelos participantes como características do seu comportamento, ao contrário de todos os outros fatores, em que as médias inferiores a 2 sugerem que as reações foram identificadas como pouco ou nada características do comportamento dos participantes. Apesar da possível influência da desejabilidade social nas respostas dos sujeitos, também é bastante plausível que esses re- 
sultados reflitam a real manifestação mais frequente de reações saudáveis e mais raras de reações patológicas e não adaptativas.

Os outros fatores (F1, F3, F4, F5 e F6) se referem a características mais patológicas do ciúme romântico. $\mathrm{O}$ fator 1 foi denominado não contato com o parceiro, por envolver o aparecimento de pensamentos sobre infidelidade (reações cognitivas) diante da perda de controle sobre a localização do parceiro. Os itens desse fator, portanto, descrevem apenas a ausência do parceiro, e não uma cena em que a interação parceiro-rival é constatada. Portanto, o surgimento de pensamentos relacionados com a infidelidade do parceiro parece envolver uma ameaça imaginada ao relacionamento e/ou a suspeita paranoide de estar sendo traído/a, características que costumam estar associadas ao ciúme patológico (Pfeiffer \& Wong, 1989). Esse fator é compatível com o F4 (Desconfiança) da escala anterior (Carvalho et al., 2008). Porém, a criação de mais itens resultou num fator mais consistente e representativo, já que o número de itens subiu de 3 para 7 e o coeficiente alfa foi de 0,72 para 0,90 . Portanto, também neste fator a revisão da escala proporcionou a confirmação de um fator com esse significado, mas o incremento de itens tornou-o mais representativo e fidedigno.

Por sua vez, os fatores 3 e 4 se referem à manifestação de reações agressivas, que têm a característica de serem mais intensas e estarem relacionadas à manifestações comportamentais, como "perder as estribeiras", "armar barraco", "dar show", quebrar pertences, entre outros. Subjacente a essas reações está o sentimento de raiva, frequentemente citado com um dos que compõem a complexa reação de ciúme (De Silva, 1997; DeSteno et al., 2006; Mathes et al., 1985; Mullen, 1995). Tanto pela intensidade como pelas consequências não adaptativas da reação, esses fatores são associados à manifestação patológica do ciúme romântico.

No instrumento anterior (Carvalho et al., 2008), o F3 (Não Agressão) descrevia reações contrárias à agressividade [por exemplo, Nunca tive vontade de agredir fisicamente outra pessoa, que não fosse meu/minha parceiro(a), por problemas no relacionamento], tendo sido um dos problemas que os autores tentaram resolver com a revisão do instrumento. Nesse sentido, observou-se a obtenção de não apenas um, mas de dois fatores relacionados com a reação agressiva. Uma análise do conteúdo desses fatores revela claramente que os itens do fator 3 se referem à agressividade dirigida ao parceiro, enquanto os itens do quarto fator se referem à agressividade dirigida ao rival. De fato, Mullen (1995) referiu que tanto o parceiro quanto o rival podem ser alvos da agressividade de uma pessoa tomada pelo ciúme, embora, na prática, seja muito mais comum o ataque ao parceiro do que ao rival. A obtenção desses dois fatores mostra a sensibilidade do instrumento a essa nuance e permite levantar a hipótese de que talvez haja mecanismos psicológicos distintos influenciando a escolha do alvo da agressividade. Mas essa é apenas uma hipótese, que o presente instrumento pode ajudar a elucidar em futuros estudos sobre o tema.

O fator 5 reuniu itens que descrevem uma reação de atribuição de culpa a si mesmo pelo envolvimento do parceiro com uma terceira pessoa, e, por isso, essas reações foram associadas à baixa autoestima. Esse fator se assemelha ao F6 da escala anterior (Carvalho et al., 2008), que descrevia reações de insegurança [por exemplo, Tenho vontade de perguntar para os(as) amigos(as) do(a) meu/minha parceiro(a) se ele(a) gosta realmente de mim]. No entanto, os autores consideraram que, tal como estavam, os itens descreviam situações associadas com relacionamento amoroso, mas não necessariamente com ciúme. Portanto, a alteração das frases para reações de autoculpa e autodesvalorização frente a situações de infidelidade resultaram na formação de um fator que representa melhor uma reação disparada pela (possibilidade de) infidelidade, típica de ciúme. O coeficiente alfa, no entanto, caiu de 0,72 para 0,67 , considerado insuficiente, segundo critérios internacionais (Pasquali, 2003; Urbina, 2007). Esse fator também parece ser o que menos se afina com os demais fatores da escala atual. Apesar de ter apresentado carga no fator de segunda ordem, ela foi definidamente inferior aos demais, sugerindo uma menor relação com o construto global de ciúme.

De fato, a autoestima parece desempenhar um papel na ocorrência de ciúme um pouco diferente daquele que foi contemplado neste instrumento. DeSteno et al. (2006), na verdade, apontam que a ameaça à autoestima, e não a baixa autoestima, é que medeia a intensidade da reação de ciúme. Portanto, a reação de ciúme deve ser tanto mais intensa quanto mais a pessoa sentir a autoestima ferida. Ao contrário disso, as frases descrevem reações que sugerem baixa autoestima, e, portanto, certa aceitação do envolvimento parceiro-rival. Este é um ponto que fica por ser revisado em futuros estudos com este instrumento. É também uma possibilidade de investigação para a compreensão do papel da autoestima na reação de ciúme, pois, aparentemente, é a (alta) autoestima ferida, e não a baixa autoestima, que se associa à reação de ciúme.

Finalmente, o sexto fator reuniu itens que descrevem comportamentos de investigação. Essa reação também foi relacionada por Pfeiffer e Wong (1989) como característica do ciúme patológico, e é compatível com o F5 da escala anterior (Carvalho et al., 2008). No entanto, apesar de terem sido criados mais itens para esse fator, ele acabou ficando com apenas três, tal como havia ficado na versão original, mas com itens de conteúdos diferentes. Talvez, por isso, a fidedignidade tenha caído de 0,62 para 0,55 . Assim, a reformulação deste fator, não atingiu o objetivo do incremento da consistência interna, embora tenha confirmado a existência de um fator relacionado com esse conteúdo.

Portanto, a obtenção de fatores compatíveis com os construtos apontados pela literatura científica como relacionados ao ciúme e com fatores obtidos no estudo ante- 
rior, nos permite dizer que o instrumento apresenta evidências de validade baseadas na estrutura interna (AERA et al., 1999) Além disso, a obtenção de fatores teoricamente embasados também se apresenta como evidência de validade da própria teoria, já que as manifestações propostas teoricamente foram, de fato, captadas na população, por meio de recursos estatísticos (análise fatorial) independentes da interferência dos pesquisadores.

Entretanto, os coeficientes de fidedignidade parecem ter sofrido o efeito típico do número de itens do fator. Assim, os três primeiros fatores, compostos por seis ou sete itens, apresentaram coeficientes de consistência interna de $0,90,0,83$ e 0,81 , respectivamente, considerados como bons pela literatura da área (Pasquali, 2003; Urbina, 2007). Os três últimos fatores, com apenas três ou quatro itens, apresentaram consistência interna pouco abaixo de 0,7 , o valor tradicionalmente considerado um marco em termos de fidedignidade de instrumentos de medida.

Esses resultados sugerem a necessidade de se acrescentar mais itens a esses fatores, o que provavelmente seja suficiente para elevar os valores de consistência interna para os patamares recomendados. Entretanto, considerando a influência do baixo número de itens no cálculo da consistência interna, a pouca distância que os separa do valor desejável $(0,7)$ e o fato de o Conselho Federal de Psicologia aceitar valores superiores a 0,6 , pode-se recomendar o uso da escala para fins de pesquisa, especialmente para uma avaliação global do ciúme romântico.

Em relação aos objetivos propostos, este trabalho obteve êxito na fundamentação teórica da escala e na obtenção de fatores relacionados apenas à ocorrência de ciúme romântico (e não com a sua ausência). No entanto, as desejadas boas propriedades psicométricas ainda merecem consideração em outros estudos, dada a ocorrência de fatores com baixo número de itens e, talvez por isso mesmo, com índices de fidedignidade abaixo do recomendável. Outra limitação desse estudo é no número de participantes relativamente baixo $(N=201)$ e bastante específico (estudantes universitários de uma única instituição particular da cidade de São Paulo) empregado neste estudo, o que implica em maior cautela na generalização dos resultados para outras populações. Por isso, os resultados obtidos devem ser testados e confirmados em outras amostras de participantes.

Apesar disso, este estudo apresenta um avanço importante ao apresentar uma escala multifacetada, que congrega vários aspectos já relacionados ao ciúme romântico em estudos anteriores, mas nunca contemplados em uma mesma escala de avaliação. Incluem-se nesse caso as escalas de comportamentos de investigação, baixa autoestima e de não contato com o parceiro, por exemplo. A continuidade do desenvolvimento da escala pode ter um impacto bastante positivo no favorecimento da realização de pesquisas sobre o tema e para avaliação de aspectos psicopatológicos em situações clínicas. A rele- vância disso se torna ainda mais evidente se considerarmos a frequência e as terríveis consequências que a manifestação do ciúme têm causado em nossa sociedade.

Assim, este estudo configura-se como mais um passo no aprimoramento de uma ferramenta para avaliação do ciúme romântico. No entanto, o processo de desenvolvimento de instrumentos psicológicos dificilmente encontra um fim, isto é, deve ser sempre atualizado, sobretudo no que se refere a busca de evidências de validade e verificação dos índices de fidedignidade (Urbina, 2007). Nesse sentido, espera-se que este trabalho possa dar base para futuros estudos utilizando o ICR-R em outros contextos e com outras amostras, ampliando o conhecimento acerca das propriedades psicométricas do instrumento.

\section{Referências}

Almeida, T., Rodrigues, K. R. B., \& Silva, A. A. (2008). O ciúme romântico e os relacionamentos amorosos heterossexuais contemporâneos. Estudos de Psicologia (Natal), $13,83-90$.

American Educational Research Association, American Psychological Association, \& National Council on Measurement in Education. (1999). Standards for educational and psychological testing. Washington, DC: American Educational Research Association.

American Psychiatric Association. (2003). Manual Diagnóstico e Estatístico de Transtornos Mentais - DSM-IV-TR (D. Batista, Trad.). Porto Alegre, RS: Artmed.

Benedictson, C. (1977). The development of a Scale for the Assessment of Jealousy. Paper presented at the meeting of the Southeastern Psychological Association, Hollywood, FL.

Bryson, J. B. (1976). The nature of sexual jealousy: An exploratory study. Paper presented at the meeting of the American Psychological Association, Washington, DC.

Bryson, J. B. (1977). Situational determinants of the expression of jealousy. Paper presented at the meeting of the American Psychological Association, San Francisco, CA.

Buss, D. M., Larsen, R. J., Westen, D., \& Semmelronth, J. (1992). Sex differences in Jealousy: Evolution, Physiology, and Psychology. Psychological Science, 3, 251-255.

Buunk, B., \& Bringle, R. G. (1987). Jealousy in love relationships. In D. Perlman \& S. Duck (Eds.), Intimate relationships: Development, dynamics, and deterioration ( $\mathrm{pp}$. 123-147). Beverly Hills, CA: Sage.

Carvalho, L. F., Bueno, J. M. H., \& Kebleris, F. (2008). Estudos psicométricos preliminares do Inventário de Ciúme Romântico - ICR. Avaliação Psicológica, 7, 335-346.

De Silva, P. (1997). Jealousy in couple relationships: Nature, assessment and therapy. Behaviour Research and Therapy, 35, 973-985

Demirtas, H. A. \& Dönmez, A. (2006). Jealousy in close relationships: Personal, relational and situational variables. Turkish Journal of Psychiatry, 17, 1-11.

DeSteno, D. A., \& Salovey, P. (1996). Evolutionary origins of sex differences in jealousy? Questioning the "fitness" of the model. Psychological Science, 7, 367-372.

DeSteno, D., Valdesolo, P., \& Bartlett, M. Y. (2006). Jealousy and the Threatened Self: Getting to the heart of the greeneyed monster. Journal of Personality and Social Psychology, 91, 626-641. 
Dutton, D. G., van Ginkel, C., \& Landolt, M. A. (1996). Jealousy, intimate abusiveness, and intrusiveness. Journal of Family Violence, 11, 411-423.

Holtzworth-Munroe, A., Stuart, G. L., \& Hutchinson, G. (1997). Violent versus nonviolent husbands: Differences in attachment patterns, dependency, and jealousy. Journal of Family Psychology, 11, 314-331.

Hupka, R. B., \& Bachelor, B. (1979). Validation of a scale to measure romantic jealousy. Paper presented at the meeting of the Western Psychological Association, San Diego, CA.

Marks, M., \& De Silva, P. (1991). Multi-faceted treatment of a case of morbid jealousy. Sexual and Marital Therapy, 6, 7178 .

Masciuch, S., \& Kienapple, K. (1993). The emergence of jealousy in children 4 months to 7 years of age. Journal of Social \& Personal Relationships, 10, 421-435.

Mathes, E. W. (1992). Jealousy: The psychological data. Lanham, MD: University Press of America.

Mathes, E. W., Adams, H. E., \& Davies, R. M. (1985). Jealousy: Loss of relationship rewards, loss of self-esteem, depression, anxiety, and anger. Journal of Personality and Social Psychology, 48, 1552-1561.

Mullen, P. (1995). Jealousy and violence. Hong Kong Journal of Psychiatry, 5, 18-24.

Mullen, P. E., \& Martin, J. L. (1994). Jealousy: A community study. British Journal of Psychiatry, 164, 35-43.

Nadler, A., \& Dotan, I. (1992). Commitment and rival attractiveness: Their effects on Male and Female reactions to jealousy-arousing situations. Sex Roles, 26, 283-310.

Parker, J. G., Low, C. M., Walker, A. R., \& Gamm, B. K. (2005). Friendship jealousy in young adolescents: Individual differences and links to sex, self-esteem, aggression, and social adjustment. Developmental Psychology, 41, 235-250.

Pasquali, L. (2003). Psicometria: Teoria dos testes na Psicologia e na Educação. Petrópolis, RJ: Vozes.

Pfeiffer, S. M., \& Wong, P. T. P. (1989). Multidimensional jealousy. Journal of Social and Personal Relationships, 6, 181-196.

Pines, A. M. (1992). Romantic jealousy: Five perspectives and an integrative approach. Psychotherapy, 29, 675-683.

Pines, A. M. (1998). Romantic jealousy: Causes, symptoms, cures. New York: Routledge.

Ramos, A. L. M. (1998). Ciúme romântico: Teoria, medida e variáveis correlacionadas (Tese de Doutorado nãopublicada). Universidade de Brasília, DF.

Ramos, A. L. M., Yazawa, S. A. K., \& Salazar, A. F. (1994). Desenvolvimento de uma Escala de Ciúme Romântico. Psicologia: Teoria e Pesquisa, 10, 439-451.

Rosmarin, D. M., Chambless, D. L., \& LaPointe, K. (1979). The survey of interpersonal reactions: An inventory for the measurement of jealousy. Unpublished manuscript, University of Georgia, Athens, GA.

Rusch, P. A., \& Hupka, R. B. (1977). Development and validation of a Scale to Measure Romantic Jealousy. Paper presented at the annual meeting of the Western Psychological Association, Seattle, WA.

Soble, A. (1990). The structure of love. New Haven, CT: Yale University Press.

Torres, A. R., Ramos-Cerqueira, A. T. A., \& Dias, R. S. (1999). O ciúme enquanto sintoma do transtorno obsessivo-compulsivo. Revista Brasileira de Psiquiatria, 21(3), 165-173.

Urbina, S. (2007). Fundamentos da testagem psicológica. Porto Alegre, RS: Artmed.
Vandello, J. A., \& Cohen, D. (2003). Male honor and Female Fidelity: Implicit cultural scripts that perpetuate domestic violence. Journal of Personality and Social Psychology, 84(5), 997-1010.

Vecchio, R. P. (2000). Negative emotion in the workplace: Employee jealousy and envy. International Journal of Stress Management, 7(3), 161-179.

White, G. L. (1980). Validation of three jealousy scales. Unpublished manuscript, University of Maryland, College Partk, MD.

White, G. L. (1981). A Model of Romantic Jealousy. Motivation and Emotion, 5(4), 295-310.

White, G., \& Mullen, P. E. (1989). Jealousy: Theory, research, and clinical strategies. New York: Guilford Press.
Recebido: 26/02/2010

$1^{a}$ revisão: 09/05/2011 Aceite final: $12 / 05 / 2011$ 